\title{
Title:
}

\section{MAFLD burden on the Spanish National Health System. A call to action}

\section{Authors:}

Daniel Riado Mínguez, María Luisa Gutiérrez García, Lorena Jara Fernández

DOI: $10.17235 /$ reed.2022.8606/2022

Link: PubMed (Epub ahead of print)

Please cite this article as:

Riado Mínguez Daniel, Gutiérrez García María Luisa, Jara Fernández Lorena. MAFLD burden on the Spanish National Health System. A call to action. Rev Esp Enferm Dig 2022. doi: 10.17235/reed.2022.8606/2022.

This is a PDF file of an unedited manuscript that has been accepted for publication. As a service to our customers we are providing this early version of the manuscript. The manuscript will undergo copyediting, typesetting, and review of the resulting proof before it is published in its final form. Please note that during the production process errors may be discovered which could affect the content, and all legal disclaimers that apply to the journal pertain. 


\section{Carta 8606 inglés}

\section{MAFLD burden on the Spanish National Health System. A call to action}

Daniel Riado Mínguez, María Luisa Gutiérrez García \& Lorena Jara Fernández

Digestive Diseases Unit. Hospital Universitario Fundación Alcorcón. Alcorcón, Madrid. Spain

Correspondence: Daniel Riado Mínguez

e-mail: daniel.riado@gmail.com

Keywords: Metabolic syndrome. MAFLD. Fibrosis. Liver disease. Cirrhosis. Public health.

Conflict of interest: the authors declare no conflict of interest.

Dear Editor,

We read the editorial by Crespo et al on the foreseeable burden of metabolic associated liver disease (MAFLD) on the Spanish National Health System over the next years (1). Between $0.35-0.4 \%$ of the Spanish population has cirrhosis and more than one million people have significant fibrosis, assessed by ET $\geq 9 \mathrm{kPa}$ (2). Compared with the general population, patients with cirrhosis have more comorbidities and use healthcare resources more frequently. Recent data show a decrease of $24 \%$ in hospitalization due to cirrhosis during the period from 2005-2014 in Spain (3). These data predate the availability of direct antiviral agents against HCV. A $20 \%$ reduction of cirrhosis-related mortality during the period from 2006-2018 was observed, as with other Southern European countries (4). This decline reflects a reduction of alcohol consumption in the last decades. More recently, $90 \%$ of patients with significant liver 
fibrosis were negative for HCV or HBV, did not consume harmful amounts of alcohol and showed components of metabolic syndrome, thereby suggesting that MAFLD is the current leading cause of liver fibrosis in Spain (2). Some studies found that disadvantaged areas in the Madrid Community had higher liver-related mortality, highlighting that lower income is another socioeconomic determinant of chronic liver disease (5).

A small ecological design study was performed with data from the National Institute of Statistics (Instituto Nacional de Estadística) regarding cirrhosis mortality rate, alcohol consumption and obesity rates in the seventeen Spanish autonomous communities. Unadjusted cirrhosis-related mortality rates significantly correlated with obesity rate but not with alcohol consumption (Fig. 1).

As Crespo et al. pointed out, in most western countries, the degree of preparation for coping with this issue is insufficient (1). Optimal adherence to national guidelines on screening and treatment of MAFLD is not enough to deal with this public health matter.

Coordinated action by central and regional administrations is key, including the implementation of policies that favor healthy eating and a healthy lifestyle through the promotion of physical exercise, such as cycling and pedestrian routes, recreational areas, the promotion of public transport, taxation on sweet drinks, saturated fats and reduction of VAT on the components of the Mediterranean diet. These do not require screening by population segments and can favor overall health and specifically, the prevention of MAFLD.

\section{REFERENCES}

1. Crespo J, Iruzubieta P, Lazarus JV. Can NAFLD overwhelm the Spanish healthcare system in the years to come? Rev Esp Enferm Dig 2021;114:5-9. DOI: $10.17235 /$ reed.2021.8524/2021

2. Caballería L, Pera G, Arteaga I, et al. High Prevalence of Liver Fibrosis Among European Adults with Unknown Liver Disease: A Population-Based Study. Clin Gastroenterol Hepatol 2018;16:1138-45. DOI: 10.1016/j.cgh.2017.12.048 
3. Fernandez Rodriguez CM, Fernández Pérez C, Bernal JL, et al. RECALAD. Patient care at National Health System Digestive Care Units - A pilot study, 2015. Rev Esp Enferm Dig 2018;110(1):44-50. DOI: 10.17235/reed.2017.5316/2017

4. Blachier M, Leleu H, Peck-Radosavljevic $M$, et al. The burden of liver disease in Europe: A review of available epidemiological data. J Hepatol 2013;58:593-608 DOI: 10.1016/j.jhep.2012.12.005

5. Segura del Pozo J, Gandarillas A, Domínguez Berjón F, et al. Chronic liver disease and cirrhosis mortality and social deprivation: a spatial analysis in small areas of Madrid region. Nutr Hosp 2010;25:597-605.
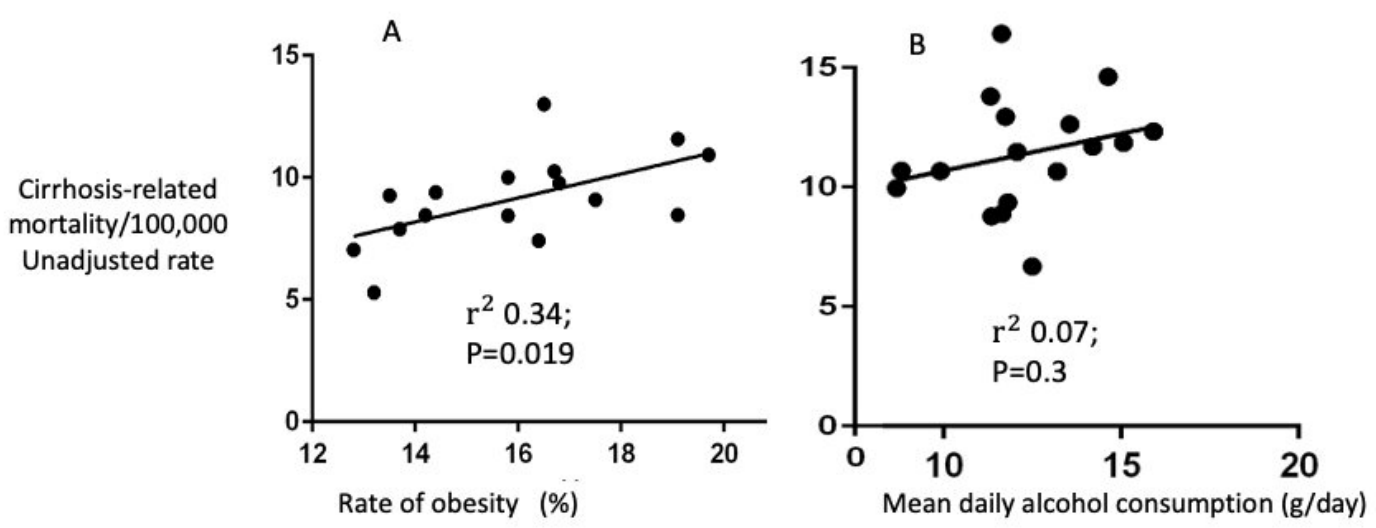

Fig. 1. Correlation between unadjusted cirrhosis-related mortality rate and obesity rate (A) or mean daily alcohol consumption (B). 